\title{
Urgences
}

\section{Poser des balises à nos chemins d'écriture}

\section{Jean Cossette}

Numéro 11, 3e trimestre 1984

URI : https://id.erudit.org/iderudit/025167ar

DOI : https://doi.org/10.7202/025167ar

Aller au sommaire du numéro

Éditeur(s)

Urgences

ISSN

0226-9554 (imprimé)

1927-3924 (numérique)

Découvrir la revue

Citer ce document

Cossette, J. (1984). Poser des balises à nos chemins d'écriture. Urgences, (11),

5-6. https://doi.org/10.7202/025167ar d'utilisation que vous pouvez consulter en ligne.

https://apropos.erudit.org/fr/usagers/politique-dutilisation/ 


\section{Poser des balises à nos chemins d'écriture}

L'écriture prévaut-elle sur la littérature? Le geste d'écrire implique-t-il nécessairement un signifié qui sera digne de passer à l'histoire? L'esthétisme en matière littéraire a-t-il toujours sa place ou devons-nous opter pour l'éclatement des tendances au risque de choquer lecteurs et critiques, praticiens et doctes pour qui la littérarité n'est ni plus ni moins que coulée dans le béton précontraint de leurs... goûts? Ces questions vous apparaîtront comme étant capitales ou futiles selon que vous accordez ou non de l'importance à l'acte d'écrire dans votre vie. Et même si vous n'écrivez pas, vous demeurez quoi qu'il en soit des consommateurs de littérature, des lecteurs à part entière. Écrire et lire, lire et écrire dans I'Est du Québec... Sommes-nous toujours en état d'urgences?

Le fait est que les numéros passent et que les écrits restent. Avec ce onzième numéro, Urgences entame une deuxième dizaine littéraire que l'on voudrait encore plus dense, plus kaléidoscopique. L'état d'urgences nous le vivons numéro après numéro et nous le vivrons aussi longtemps qu'il existera des auteurs, connus ou inconnus, qui choisiront d'emprunter nos couloirs. Une revue littéraire se construit page après page jusqu'au dernier de ses numéros. C'est en quelque sorte un monde en soi, un monde qui évolue au rythme de son temps.

Dans cette onzième urgence de dire, nous continuons notre politique adoptée en juin 1983. Un auteur invité, ici Noël Audet natif de Maria, vous présente un bel inédit. Puis d'autres écrivains de la nouvelle vague qui prennent de plus en plus de place sur le marché québécois: Michel Savard, Réal-Gabriel Bujold et plus récemment, avec son tout premier roman, JeanYves Dupuis. Ajoutons à cette brochette littéraire les textes révélateurs de Dominique Bard, Micheline Lévesque, Vianney Gallant et Yves Vaillancourt. Vous trouverez également, comme c'est d'ailleurs devenu une bonne habitude, chronique, parutions commentées, notes bio-bibliographiques sur nos auteurs ainsi que des heures d'agréable lecture. Fait à 
souligner, I'annonce de notre prochain numéro thématique: un "spécial humour»...

Chers lectrices, chers lecteurs, faut-il vous rappeler combien votre soutien moral et financier nous est essentiel pour continuer de défricher les sentiers d'une littérature encore bien jeune. Faut-il vous souligner encore une fois que sans votre présence rassurante le fait culturel qu'est l'écriture s'essoufflerait bien vite. Vos encouragements par voie d'abonnements ou de publicité, dite de bouche à oreille, nous sont des urgences au même titre que celles-là qui nous font travailler, toujours sans but lucratif, au maintien de la parole d'ici. Opter pour Urgences, c'est en quelque sorte veiller à l'épanouissement de notre culture collective. C'est baliser nos chemins de traverse.

Jean Cossette pour le Comité de Direction 